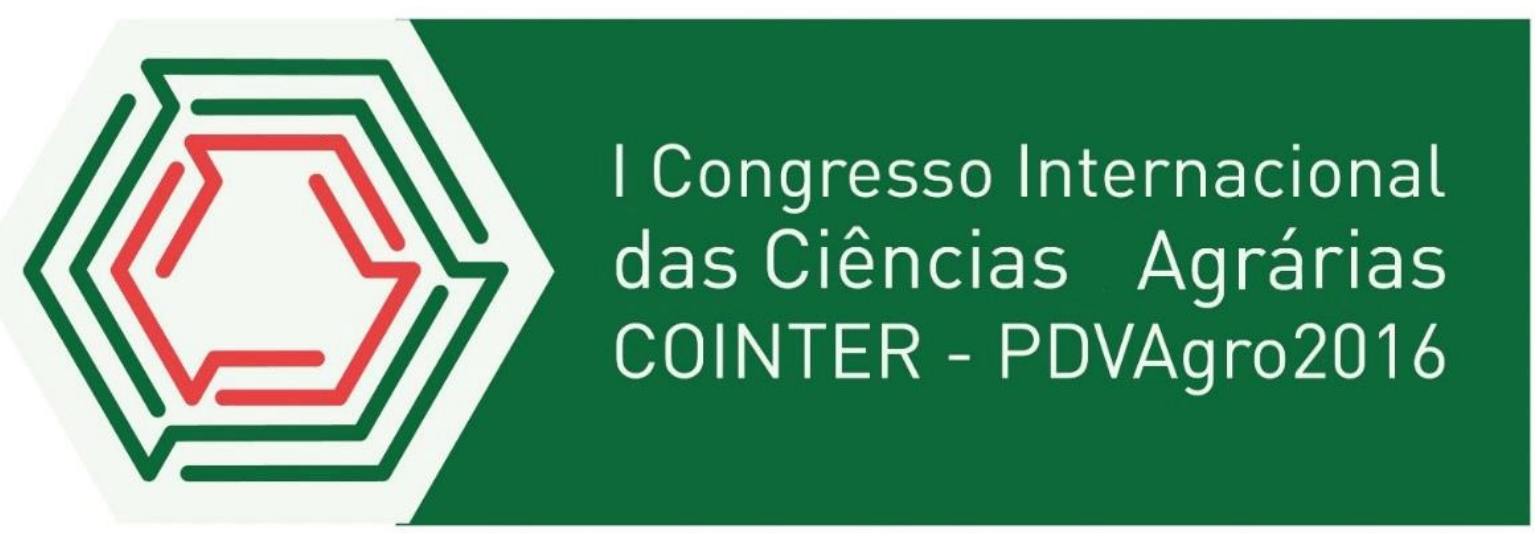

\title{
BALANCED SCORECARD APLICADO EM PEQUENAS EMPRESAS: FERRAMENTA DE GESTÃO ESTRATÉGICA
}

\author{
Apresentação: Comunicação Oral \\ Marcelo da Costa Borba ${ }^{1}$; Elenice da Silva Moraes ${ }^{2}$; Josefa Edileide Santos Ramos ${ }^{3}$; Hélio \\ Luiz Beretta Dal Monte ${ }^{4}$; Rodolfo Araújo de Moraes Filho ${ }^{5}$
}

\section{RESUMO}

Este trabalho consiste em um estudo de caso em uma empresa do setor comercial varejista localizada no município de Serraria no estado da Paraíba tendo como objetivo elaborar uma proposta de implantação do Balanced Scorecard (BSC). No desenvolvimento da proposta foram contempladas cinco tarefas: 1. Preparação do ambiente de aplicação; 2. Conhecimento da organização e preparação do processo de discussão; 3. Definição de objetivos estratégicos; 4. Estabelecimento dos indicadores para as perspectivas, metas de superação e planos de ação; 5. Preparação para implantação e aprovação final. Embora não se tenha implantado a metodologia propriamente dita na empresa investigada, convém destacar contribuições importantes no processo de execução das fases iniciais do Balanced Scorecard. Os resultados mostraram que existe a possibilidade da implantação do BSC, desde que seja adaptado à realidade da pequena empresa varejista. Sua implantação requer que sejam superadas algumas barreiras para se utilizar o BSC no processo estratégico de uma pequena organização, como indisponibilidade de recursos financeiros e humanos e a ausência de uma cultura voltada ao pensamento a longo prazo.

\section{INTRODUÇÃ̃O}

O Balanced Scorecard (BSC) foi inicialmente desenvolvido como instrumento de auxílio aos gestores para alcançar sucesso empresarial a longo prazo. Oferece aos empresários instrumental necessário para planejar e controlar as etapas de planejamento das atividades

\footnotetext{
1 Programa de Pós-Graduação em administração e Desenvolvimento Rural, Universidade Federal Rural do Pernambuco, marccelodacosta@gmail.com

2 Programa de Pós-Graduação em administração e Desenvolvimento Rural, Universidade Federal Rural do Pernambuco, elenicemoraes7@gmail.com

3 Programa de Pós-Graduação em administração e Desenvolvimento Rural, Universidade Federal Rural do Pernambuco, edileideramos@gmail.com

$4 \quad$ Bacharelado em administração, Universidade Federal da Paraíba, heliodalmonte@gmail.com

5 Doutor em Administração, Universidade Federal Rural do Pernambuco, rodolfoamfilho@yahoo.com.br
} 
objetivando implementar uma gestão estratégica com vistas a alcançar sucesso empresarial. O BSC foi desenvolvido inicialmente para grandes corporações, no entanto, busca-se aqui adaptar sua aplicação para o caso de uma pequena empresa.

Essa ferramenta traduz a missão e a estratégia de uma empresa em um conjunto abrangente de medidas de desempenho, servindo de base para construção de um sistema de medição da eficácia da gestão estratégica da firma, perseguindo os objetivos financeiros entre outros, e incluindo os vetores de desempenho desses objetivos (HUANG, 2009). Segundo Souza (2003), o Balanced Scorecard quando utilizado como ferramenta de gestão estratégica, possibilita às empresas, através da mobilização a exploração dos ativos intangíveis com intuito de desenvolver sua capacidade em alcançar uma boa estratégia de longo prazo préestabelecida.

Visou-se com esse trabalho, a implantação do BSC como sistema de gestão estratégica procurando adequar sua metodologia ao contexto de uma empresa de pequeno porte, de formas a melhor auxilia-la no processo de acompanhamento e controle da tomada de decisão. $\mathrm{O}$ setor escolhido para o caso em estudo foi o do seguimento comercial varejista. $\mathrm{O}$ artigo encontra-se estruturado em cinco seções, a saber: (i) introdução, (ii) referencial teórico, que aborda os conceitos principais do BSC como sistema de gestão estratégica e sua implantação em pequenas empresas, (iii) procedimentos metodológicos adotados para a realização da pesquisa; (iv) apresentação e análise dos resultados, e, como último item (v), as considerações finais.

\section{REFERENCIAL TEÓRICO}

Nesta secção, será discutido e apresentado o BSC como ferramenta de gestão estratégica em apoio à tomada de decisão da firma, bem como sua implantação em pequenas empresas.

\subsection{Aspectos conceituais do Balanced Scorecard (BSC)}

O Balanced Scorecard foi desenvolvido por volta do ano de 1990 e consolidados em publicações a partir de 1996, através de estudos feitos por Robert Kaplan e David Norton evidenciando que indicadores financeiros não apresentam informações suficientes para a condução do negócio (OTTOBONI, 2002). O BSC é uma abordagem de gestão estratégica que consiste em diferentes indicadores, buscando contemplar medidas financeiras com outras 
não financeiras, equilibrando objetivos de curto e longo prazos a indicadores de tendências e de ocorrências (KAPLAN e NORTON, 2001).

Neste contexto, o Balanced Scorecard busca trabalhar quatro perspectivas distintas, que se complementam entre si, a saber: I - perspectiva financeira: observando a gestão estratégica de custos e permitindo o crescimento de receita; II - perspectiva do cliente: considerando sua satisfação; III - perspectiva dos processos internos: através da busca por excelência de desempenhos nos processos chaves para o empreendimento; IV - perspectiva de aprendizagem e crescimento: inovação através das pessoas. Essa divisão permite combinar princípios, a fim de definir metas de curto prazo, almejando um valor de longo prazo (KAPLAN e NORTON, 2004).

\subsection{Balanced Scorecard como Sistema de Gestão Estratégica}

Para Kaplan e Norton (2004), a gestão estratégica de uma organização demostra como a organização pretende criar valor para seus acionistas, funcionários, clientes e cidadãos. Ela representa um processo contínuo lógico que movimenta toda a organização, desde a declaração da missão até o trabalho executado pelos empregados de linha. Sua implantação parte do princípio de que não envolve decisões futuras e sim a futuridade das decisões atuais (RATNASINGHAM, 2009). Com efeito, o que interessa ao administrador ou aos profissionais da área de gestão são os efeitos que suas decisões atuais terão em um futuro previsível. As consequências e efeitos futuros desejados são as molas propulsoras do ato de decidir o agora (DRUCKER, 2003).

Mintzberg e Quinn (2006), no intuito de representar a gestão estratégica em um conceito mais abrangente, conceitua ela em cinco diferentes perspectivas: plano, padrão, posição, perspectiva e truque. Em que Plano representa as ações conscientemente articuladas afim de lidar com uma determinada situação; Padrão dispõe sobre a consistência no comportamento ao longo dos anos, sempre inspirado em algo extraído de seu passado; Posição está voltada para o nicho de mercado pretendido pela empresa possibilitando um retorno econômico superior aos demais concorrentes; Perspectiva simboliza a maneira natural da organização em fazer as coisas; e o Truque representa habilidade própria de superar os concorrentes (HUANG, 2009).

\subsection{Balanced Scorecard em Pequenas Empresas}

As pequenas empresas estão presentes em todas as partes do país, sendo elas reconhecidas pelo importante papel na geração de emprego e renda, disputando a preferência 
no mercado consumidor. Para o SEBRAE (2013) as transformações tecnológicas alinhadas ao aumento de demanda de bens de consumo e serviços, têm gerado mudanças progressivas na distribuição de renda. Esses fatores contribuem para que as MPE's assumam papel ainda mais significativo na geração de postos de trabalho, tendo gerado no Brasil entre os anos de 2002 a 2012, cerca de 6,6 milhões de empregos. Neste contexto Oliveira (2001), afirma que as pequenas empresas possuem características próprias como: contribuição na geração do produto nacional, absorção de mão-de-obra, geração de renda, flexibilidade de localização e composição do capital nacional. Outra peculiaridade marcante das MPE's está relacionado a sua administração, em que seus proprietários são representados por uma única pessoa ou um grupo pequeno de indivíduos. Em que ações relativas às áreas de gestão são exercidas de forma cumulativa por poucas pessoas, quando não, por uma única pessoa, o empresário (RASILA, JOHANNA e NENONEN, 2010).

Com a popularização e evolução do BSC como ferramenta de gerenciamento estratégico, muitos estudos foram desenvolvidos com o intuito de atender a diferentes contextos organizacionais. Com isso, para a aplicação do Balanced Scorecard na empresa, foram previamente analisados os modelos apresentados por Kaplan \& Norton (1997), Richards (1998), Campos (1998); Olve, Roy e Wetter (2001) e Soares (2001). Observa-se, no entanto, que a maioria desses estudiosos mantiveram sua abordagem para o contexto das grandes instituições. Sendo assim, a etapa de desenvolvimento da metodologia na empresa estudada seguirá os estudos de Silva (2011), que além de comparar outros estudos, desenvolveu um modelo resumido/prático para ser aplicado em micro e pequenas empresas. $\mathrm{O}$ BSC aplicado à pequenas empresas, segundo Silva (2011) deve ser constituído de três etapas, a saber: Preparação, Elaboração e Implantação.

\section{PROCEDIMENTOS METODOLÓGICOS}

A pesquisa do ponto de vista dos objetivos pode ser considerada como sendo de natureza exploratória e descritiva. A pesquisa exploratória se impõe sempre que não se tem muita informação sobre o objeto em estudo, aqui justificado pela aplicação experimental do BSC em ambiente de uma pequena empresa, reconhecidas suas limitações. Quanto ao método de análise dos dados pode-se classificar a pesquisa como sendo qualitativa. Para levantamento dos dados foram utilizados como procedimentos técnicos a pesquisa documental (planejamento estratégico institucional) e o levantamento de dados primários e secundários. Para o levantamento dos dados primários as técnicas de entrevistas ocorreram com aplicação de questionários diretos aplicado ao responsável pelo empreendimento. Sendo utilizada uma 
entrevista semiestruturada, com questões objetivas e roteiro previamente determinado. Como também foi feita uma entrevista informal ou não estruturada, com intuito de proporcionar uma visão geral do problema pesquisado.

Em relação aos dados secundários, houve ainda o levantados por meio de protocolo resumido, conhecido como checklist objetivando atingir resultados essenciais ao desenvolvimento da pesquisa. Para a elaboração do instrumento de coleta foram utilizados tópicos referentes à descrição da organização; aos produtos, serviços e sistemas; à força de trabalho; aos clientes e mercados e aos fornecedores. Foram feitas perguntas diretamente aos respondentes cujas respostas foram registradas e logo em seguida avaliadas para a construção das considerações do pesquisador sobre o assunto estudado.

Em relação à técnica de pesquisa, optou-se pelo estudo de caso, selecionando uma organização para a realização de análise. Esse método é aconselhado quando uma situação geral pode ser melhor entendida, a partir da análise em profundidade de uma situação particular ou caso específico (MARCONI e LAKATOS, 2003). O ambiente escolhido para estudo foi o de uma empresa do setor de comércio varejista de alimentos, localizada no município de Serraria, microrregião do brejo paraibano. Os sujeitos da pesquisa foram o gestor, funcionários e clientes da pequena empresa. A escolha da pequena empresa para desenvolvimento desta pesquisa foi motivada pela acessibilidade aos dados necessários para a construção do sistema de medição e pela disposição de seu proprietário em participar do experimento. Já o que motivou a construção da proposta foi a possível definição de uma estratégia que ajudasse a organização a enfrentar as atuais situações e dar continuidade a suas atividades.

O estudo de caso foi realizado em três etapas. Inicialmente, foi realizada entrevista não estruturada com o gestor com intuito de reunir informações sobre a pequena empresa. Em seguida procedeu-se a análise do planejamento estratégico institucional e formulação das hipóteses estratégicas. Na fase seguinte, foram conduzidas entrevistas com todos os funcionários e alguns clientes utilizando para isso questionário previamente estabelecido, com intuito de levantar os fatores de causa e efeito dos fatores estratégicos. A pesquisa foi realizada no período de outubro a dezembro de 2014. A análise dos dados se deu através da técnica de análise de conteúdo das entrevistas e observações efetuadas em campo.

\section{APRESENTAÇÃO E ANÁLISE DOS RESULTADOS}

Nesta seção, são apresentados os dados coletados com o experimento e o resultado da pesquisa. 


\subsection{Apresentação dos dados}

A atividade de desenvolvimento da proposta de implantação do Balanced Scorecard em uma empresa de pequeno porte partiu da tentativa de aplicar a metodologia considerando algumas variáveis de sucesso preponderante dentro do processo de gerenciamento estratégico de grandes empresas. Sendo assim, o trabalho foi desenvolvido a partir da adaptação no contexto de uma pequena organização empresarial. A seguir, serão apresentados os principais resultados do estudo de caso.

\section{a) Etapa I - Preparação}

Tarefa 1. Preparação do ambiente de aplicação

Na única tarefa da fase de preparação, o empresário junto com seus funcionários teve a oportunidade de conhecer o BSC, através de reunião onde houve o repasse de informações sobre a metodologia proposta. Nessa tarefa ocorreu também o esclarecimento de muitas dúvidas geradas principalmente sobre como o BSC poderia ajudar o empreendimento ou mesmo como gerar resultado prático nas pequenas empresas. Neste encontro foi elaborado o cronograma para o desenvolvimento das etapas de preparação e elaboração.

Quadro 2. Cronograma de preparação e Elaboração

\begin{tabular}{|l|l|}
\hline Nome da tarefa & Duração \\
\hline Etapa I - Preparação & $\mathbf{2}$ dias \\
\hline Tarefa 1. Preparação do ambiente de aplicação & 2 dias \\
\hline Etapa II - Elaboração & $\mathbf{2 2 ~ d i a s ~}$ \\
\hline Tarefa 2. Conhecimento da organização e preparação do processo de discussão & 12 dias \\
\hline Tarefa 3. Definição de objetivos estratégicos & 2 dias \\
\hline $\begin{array}{l}\text { Tarefa 4. Estabelecer indicadores para as perspectivas, metas de superação e } \\
\text { planos de ação. }\end{array}$ & 3 dias \\
\hline Tarefa 5. Preparação da Implantação e aprovação final & 5 dias \\
\hline Período Total (dias úteis) & $\mathbf{2 4 ~ d i a s ~}$ \\
\hline
\end{tabular}

Fonte: Pesquisa direta, 2014

O quadro 2, apresenta a descrição em dias úteis da proposta de implantação do BSC na pequena empresa. Esse prazo considerado curto é principalmente devido ao pequeno número de pessoas envolvidas no processo e complexidade da estrutura empresarial. Segundo Silva (2011), estima-se em torno de quatro a seis semanas em contrapartida a uma grande empresa que pode ter o planejamento inicial desenvolvido entre doze a quatorze semanas.

\section{b) Etapa II - Elaboração}

Tarefa 2. Conhecimento da organização e preparação do processo de discussão

Essa tarefa teve por objetivo identificar as características da empresa, com o intuito de tornar mais explícitas a missão, a visão e a estratégia da empresa. Cabe salientar que a 
organização em estudo possuía um planejamento estratégico formal, elaborado um ano antes 2012, sendo necessário redefinir alguns pontos em decorrência das mudanças no mercado.

Tarefa 3. Definição de objetivos estratégicos

Foram desenvolvidos dois objetivos de cada perspectiva sendo: financeira impulsionar crescimento de vendas, reduzir a inadimplência; clientes - assegurar a fidelidade dos clientes, melhorar o atendimento ao cliente; processos internos - controlar a qualidade dos produtos, agilizar o processo de reposição de mercadorias nas prateleiras; aprendizado e crescimento - capacitar e desenvolver os colaboradores, ampliar o patrimônio.

Tarefa 4. Estabelecer indicadores para as perspectivas

A partir das informações colhidas, buscou-se estabelecer para as quatro perspectivas seus respectivos objetivos estratégicos, relacionados com indicadores, fatores críticos, planos de ação e metas de superação, servindo de base/apoio ao plano para funcionamento. Ao criar um painel de informações a serem colhidas em cada setor, a expectativa é esta sempre de acordo com os objetivos estratégicos pré-estabelecidos.

Tarefa 5. Preparação da implantação e aprovação final

Esta fase representou a última tarefa da elaboração do Balanced Scorecard em que novamente com o proprietário foi apresentado um plano de gestão constituído a partir da seleção das informações colhidas na secção anterior. Neste plano todos os funcionários puderam visualizar as perspectivas com seus respectivos objetivos estratégicos relacionados com indicadores, fatores críticos, planos de ação e metas de superação para que o plano possa ser colocado em funcionamento.

Figura 1: Mapa Estratégico

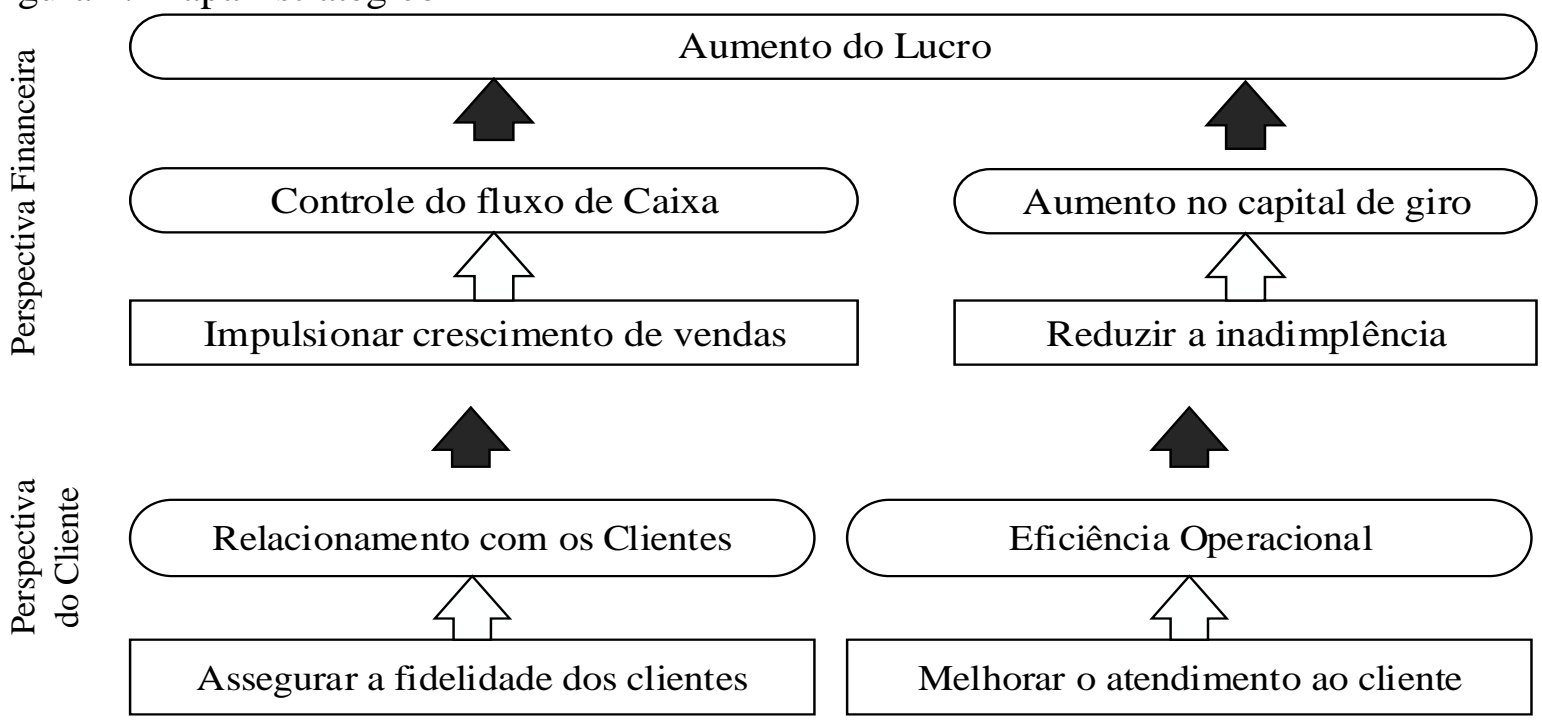




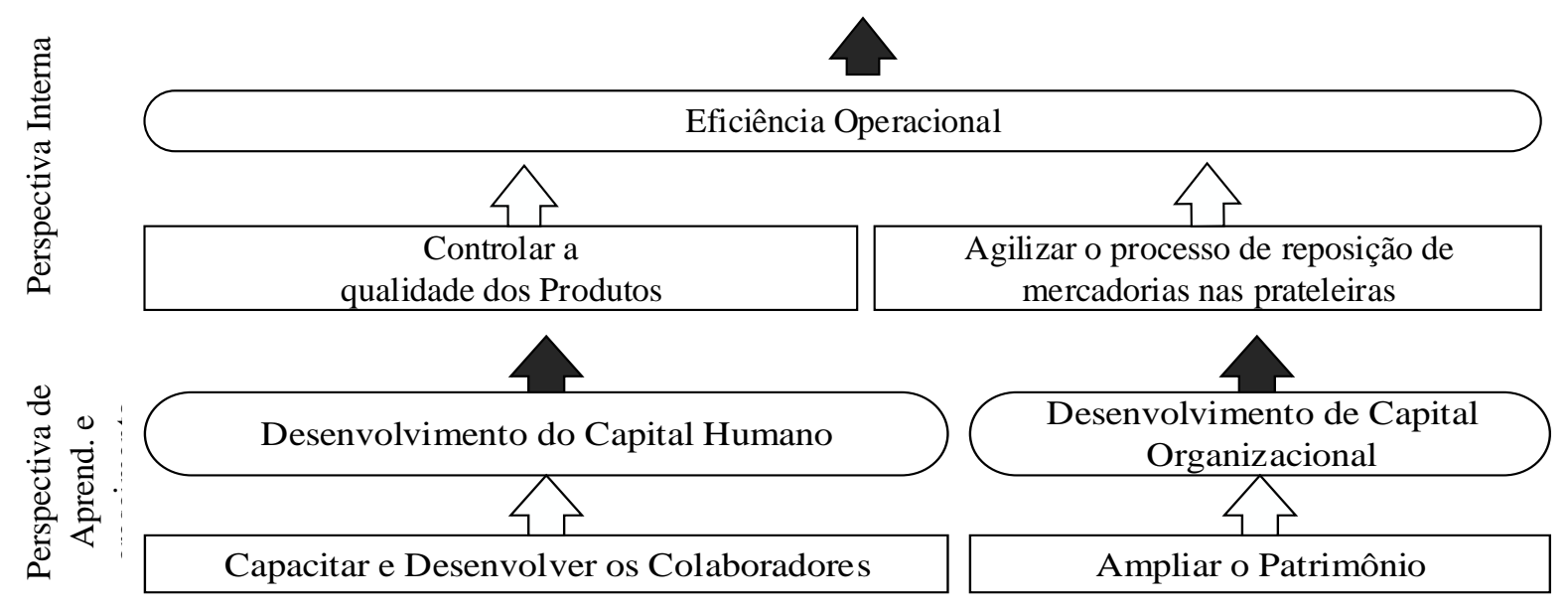

Fonte: Pesquisa direta

$\mathrm{Na}$ perspectiva financeira, a estratégia de impulsionar o crescimento de vendas e reduzir a inadimplência, onde utilizam-se indicadores financeiros tradicionais como margem de lucro operacional, redução de custos, giro do ativo. Essas medidas mostrarão se a estratégia da empresa está caminhando para o sucesso ou o fracasso. Segundo Kaplan e Norton (2004), com o Balanced Scorecard, os objetivos financeiros passam a estar explícitos e são acompanhados em seu dia-a-dia, de tal forma que ao final do longo prazo eles efetivamente tenham sido alcançados, degrau a degrau. Apesar de serem utilizados somente dois indicadores financeiros, no Balanced Scorecard, seu acompanhamento é constante, assim como o acompanhamento das causas que provocam as variações.

A perspectiva do cliente ficou voltada para assegurar a fidelidade dos clientes e melhoria no atendimento aos clientes com seus serviços de tele atendimento e pronta entrega desta forma, atrair e reter um maior número deles, conseguindo aumentar a receita e melhorar a utilização dos ativos propostos na perspectiva financeira. Segundo Kaplan e Norton (2004 p.85): "Os clientes da empresa são a fonte dos resultados financeiros, bem como, a razão de existirem os processos internos. Assim, a conexão dos clientes com as outras perspectivas é necessária para a construção do resultado central do negócio.”

A melhoria no atendimento ao cliente está voltada para atingir os objetivos da perspectiva financeira, sendo um ponto de partida para a elaboração da perspectiva dos processos internos. Essa perspectiva procurou identificar os fatores críticos de sucesso (relacionamento com o cliente e eficiência operacional) que são fatores que exercem influência na decisão de compra do cliente, e, automaticamente impactam nos resultados da empresa. 
A perspectiva do aprendizado e crescimento organizacional está voltada para a capacitação e desenvolvimento dos colaboradores com o intuito gerar melhores resultados. Para que fosse possível alcançar os objetivos sugeridos nas outras três perspectivas, foi constatada a necessidade de desenvolvimento do capital humano, organizacional definindo assim a perspectiva do aprendizado e crescimento como o alicerce do mapa estratégico da organização. Sintetizando, colaboradores capacitados e motivados, estarão aptos a melhorar a eficácia dos processos da empresa, bem como influenciarão na captação, retenção e satisfação dos clientes, e consequentemente, no aumento da receita, na redução inadimplência. Cabe salientar que nas relações de causa e efeito do Mapa Estratégico, pode-se verificar que todas os objetivos estratégicos estão direcionados para o resultado final, que no caso da empresa estudada que é o aumento do lucro.

\subsection{Analise dos resultados}

Ao desenvolver os fatores estratégicos financeiros a empresa centralizou suas ações em: aumento na receita de vendas e reduzir a inadimplência. Para que a empresa possa impulsionar o aumento da receita de vendas, terá inicialmente que organizar seu fluxo de caixa, para que isso ocorra a condição de se estabelecer uma base de informações se faz necessário, que pode ser um software para integrar as análises e os acompanhamentos de vendas, estoques, custos, contas a pagar, contas a receber, inadimplência, fluxo de caixa, orçamento, cadastro de clientes e fornecedores.

Essa base de informações possibilitará a fácil utilização dos dados do software para oferecer produtos em promoções e novas formas de pagamento, já que isso não é feito por insuficiência de informações de entrada e saída de mercadorias. Cabe ainda salientar que através do controle do fluxo de caixa haverá um gerenciamento de lucro/prejuízo por produto ou serviço. Em relação ao segundo objetivo estratégico na perspectiva financeira condiz em reduzir a inadimplência, para essa real situação será necessário a elaboração de ações como cadastramento de clientes para vendas a prazo.

Esta perspectiva dará a empresa, a certeza do rumo que está seguindo, uma vez que havendo um sistema de controle financeiro poderá projetar resultados a serem atingidos para que seguindo a literatura do Balanced Scorecard e sua proposta de implantação, possa gerar retorno financeiro com a diminuição da inadimplência e, consequentemente, aumento do faturamento empresarial.

A análise da perspectiva do cliente pelo gestor demostrou uma preocupação de assegurar a fidelidade a ponto de cada vez mais garantir as perspectivas financeiras. Sendo 
assim, os planos de ações estabelecidos para a flexibilização dos clientes passa por desenvolver pesquisas de satisfação, melhorar os serviços prestados, criar um ponto de sugestões e reclamações. Para a perspectiva de processos internos foram o controle da qualidade dos produtos e a agilidade do processo de reposição de mercadorias nas prateleiras. Estes objetivos fazem parte de um processo fundamental para a empresa uma vez que sua atividade tem impacto direto com os objetivos empresariais e principalmente com aquele que é a razão da existência da empresa, o cliente.

$\mathrm{Na}$ perspectiva do aprendizado e crescimento o desenvolvimento da empresa e a capacitação e desenvolvimento dos colaboradores nesta perspectiva é a certeza de maximização de resultados em relação ao capital humano, pois assim as pessoas estarão melhorando seu desempenho operacional, desta forma também o bom serviço prestado pela empresa resultará numa ampliação da carteira de clientes e consequentemente na maximização de resultados empresariais, ou seja com isso espera-se que fique mais uma vez comprovado que o melhor caminho para obtenção de ótimos resultados e a capacitação e desenvolvimento de pessoa.

\section{CONCLUSÃO}

Pode-se concluir que os conceitos de sistema de gestão - BSC, uma vez adaptados podem ser aplicados às pequenas empresas para orientá-las no desenvolvimento da gestão estratégia, permitindo assim, que possam apresentar vantagens competitivas em relação aos seus concorrentes no mercado. De modo que o BSC ajuda na análise de fatores interrelacionados, pois assumir que a sobrevivência de um pequeno negócio depende da sua saúde financeira que, por sua vez, depende da capacidade dos gestores atenderem às necessidades dos clientes e as demandas do mercado como processo externos, bem como, ter processos internos bem definidos.

A elaboração da proposta constatou desde a sensibilização e conscientização das pessoas, cedeu espaço à motivação pelo conhecimento do melhor funcionamento. Portanto, ter um modelo de gestão do desempenho para uma pequena empresa faz com que o gestor possa visualizar com mais facilidade os objetivos estratégicos, de forma coerente e relacionada.

Portanto, o estudo de caso vem confirmar que o BSC pode se beneficiar, no auxilio e no processo de gerenciamento estratégico. Através dessa ferramenta, a pequena empresa em estudo poderá estruturar um sistema de informação que considere os objetivos empresarias e sua capacidade de crescimento alinhada à tomada de decisão. 


\section{REFERENCIAS}

CAMPOS, J. A. Cenário Balanceado: painel de indicadores para a gestão estratégica dos negócios. São Paulo: Aquariana, 1998.

DRUCKER, P. F. Prática da Administração de Empresa. São Paulo: Pioneira, 2003.

FERRAZ, R. C. Proposta de implantação do Balanced Scorecard para uma pequena empresa: estudo impírico com enfoque nas principais dificuldades encotradas. Universidade Estadual da Paraíba. Campina Grande, p. 62. 2010.

HUANG, H. C. Designing a knowledge-based system for strategic planning: A balanced scorecard perspective. Expert Systems with Applications, v. 36, n. 1, p. 209-218, 2009.

KAPLAN, R. S.; NORTON, D. P. A Estratégia em Ação: Balaced Scorecard. Tradução de L. E. FRAZÃO FILHO. $6^{\text {a }}$. ed. Rio de Janeiro: Elsevier, 1997.

KAPLAN, R. S.; NORTON, D. P. Organização orientada para a estratégia: como as empresas do Balaced Scorecard proporcionam o novo ambiente de negócios. Rio de Janeiro: Campus, 2001.

KAPLAN, R. S.; NORTON, D. P. Kaplan e Norto na Prática. Rio de Janeiro: Campus, 2004.

MARCONI, M. A.; LAKATOS, E. M. Informe cientifico. In: Fundamentos de metodologia cientifica. $3^{\text {a }}$. ed. São Paulo: Atlas, 2003.

MINTZBERG, H.; QUINN, J. B. O processo da Estratégia. Porto Alegre. 2006.

OLVE, N. G.; ROY, J.; WETTER, M. Condutores de performance: um guia prático para o uso do Balanced Scorecard. Rio de Janeiro: Qualitymark, 2001.

OTTOBONI, C. Uma proposta de abordagem metodológica para a implantação do Balanced Scorecard (BSC) em pequenas empresas. Universidade Federal de Itajubá. Itajubá. 2002.

RASILA, H.; JOHANNA, A.; NENONEN, S. Using balanced scorecard in operationalising. Journal of Corporate Real Estate, v. 12, n. 4, p. 279-288, 2010.

RATNASINGHAM, P. ervice quality management applying the balanced scorecard: an exploratory study. International Journal of Commerce and Management, v. 19, n. 2, p. 127-136, 2009.

RICHARDS, S. A Implementação da Estratégia utilizando o Referencial de Gerenciamento do Balanced Scorecard. Campinas: Dom Cabral, 1998.

SEBRAE. Sistema Brasileiro de Apoio as Micro e Pequenas Empresas. Estudos e pesquisas legislação básica da micro e pequena empresa, 2014. Disponivel em: 
<http://www.sebrae.com.br/br/aprendasebrae/estudosepesquisas.asp>. Acesso em: 15 Março 2014.

SILVA, L. M. M. O Balanced Scorecard como instrumento de gestão estratégica e controle em pequenas empresas. Universidade Federal do Rio Grande do Sul. Porto Alegre. 2011.

SOARES, C. R. D. Desenvolvimento de uma sistemica de elaboração do Balanced Scorecard (BSC) em pequena empresa. Universidade Federal do Rio Grande do Sul. Porto Alegre, p. 132. 2001.

SOUZA, A. B. Projetos de investimento de Capital: elaboração, análise, tomada de decisão. São Paulo: Atlas, 2003. 